\title{
Motor Neuropathy in Hypothyroidism: Clinical and Electrophysiological Findings
}

\author{
Sabina Yeasmin'1, Noorzahan Begum², Shelina Begum ${ }^{3}$ \\ ${ }^{1}$ Associate Professor of Physiology, Dhaka Community Medical College, Dhaka. ${ }^{2}$ Professor and Chairman, Department of Physiology, Bangabandhu \\ Sheikh Mujib Medical University, ${ }^{3}$ Professor, Department of Physiology, Bangabandhu Sheikh Mujib Medical University, Shahbagh, Dhaka
}

\begin{abstract}
:
Background: Hypothyroidism is a clinical condition associated with low levels of thyroid hormones with raised TSH. Peripheral neuropathy may be associated with hypothyroidism which usually develops insidiously over a long period of time due to irregular taking of drugs or lack of thyroid hormone replacement ${ }^{1}$. Objectives: The present study was done to evaluate the clinical and electro-physiological findings in hypothyroid patients in order to evaluate the neuromuscular dysfunction as well as motor neuropathy. Method: In this study, 70 subjects with the age range from 20 to 50 years of both sexes were included of whom 40 hypothyroids were taken in study group (B) with the duration of 6 months to 5 years and 30 healthy euthyroid subjects were taken as control (Group A). On the basis of their TSH level, group B was further divided into group $\mathrm{B}_{1}$ with TSH level $<60 \mathrm{MIU} / \mathrm{L}$ (less severe) and group $\mathrm{B}_{2}$ with TSH $>60 \mathrm{MIU} / \mathrm{L}$ (severe group). The d latency and NCV for motor nerve function were measured by NCV machine in median and ulnar nerve for upper limb and in common peroneal nerve for lower limb. $\mathrm{TT}_{3}, \mathrm{TT}_{4}$ were measured by RIA and TSH by IRMA method. All these parameters were measured on the day 1 (one) of their first visit. Data were analysed statistically by ANOVA and $\mathrm{Z}$ test. Result: Both $\mathrm{TT}_{3}, \mathrm{TT}_{4}$ levels were significantly $(\mathrm{P}<0.01)$ lower in hypothyroids in comparison to those of control. Diminished or absence of most of the deep tendon reflexes were found in all the hypothyroids. Most of the patients (67.5\%) showed significantly higher $(\mathrm{P}<0.01)$ motor distal latencies (MDL) with lower $(\mathrm{P}>0.001)$ conduction velocities (MNCV) and all these changes were more marked in group $\mathrm{B}_{2}$. Conclusion: So, the study revealed that motor neuropathy may be a consequence of hypothyroidism.
\end{abstract}

Key Words: Hypothyroidism, neuropathy, electrophysiology

[BSMMU J 2008; 1(1): 15-18]

\section{Introduction:}

The thyroid hormones maintain the various metabolic functions by stimulating the $\mathrm{O}_{2}$ consumption in most of the cells of our body and are also necessary for their normal growth and maturation. The thyroid gland though is not essential for life; its absence causes mental and physical growth retardation. It may be also due to some intrinsic disorders in thyroid or pituitary or hypothalamus. ${ }^{1-3}$

The investigators studied nerve conduction parameters in hypothyroid patients to observe the incidence of neuropathy and functional status of peripheral nerves in thyroid deficiency. ${ }^{4-6}$ Most of them had shown that deficiency of thyroid hormones cause motor neuropathy by affecting different peripheral nerves but more commonly the median nerve. The common nerve conduction parameters done by the investigators include

Address of Correspondence: Dr. Sabina Yeasmin, Associate Professor of Physiology, Dhaka Community Medical College, Dhaka. motor distal latencies (MDL), Motor conduction velocities (MNCV) in different peripheral nerves. Motor conduction impairment of the nerve revealed by the increased MDL and decreased MNCV in that nerve. In thyroid deficiency, the nerve conduction impairment is frequent in late stage of neuropathy and the common complaints are usually weakness of muscles of the limbs followed by the atrophy of the affected muscles supplied partially or completely by the nerves. ${ }^{4-6}$

A good number of patients are suffering from thyroid deficiency which varies from mild to its severe form in our country. ${ }^{7}$ Due to lower socioeconomic status and illiteracy, most of the patients were not aware about the consequences as well as the complications of delayed or irregular treatment. Again, occurrence of neuropathy may have some relationship with the severity of thyroid deficiency ${ }^{2}$; so they need to be more conscious about 
complications of the disease. A few published data are available regarding the normal values of nerve conduction parameters of healthy Bangladeshi population, ${ }^{8}$ but no published data has yet to be found on these aspects in hypothyroid patients.

Therefore, the study has been done to find out the motor nerve conduction status of some peripheral nerves as well as to evaluate presence of motor neuropathy in hypothyroid patients. Again, this study may also give a guideline to the physicians for proper and better management of hypothyroids and also to create awareness among this group of patients so that they can take early and regular treatment and thereby minimizes the occurrence of the neuropathy in hypothyroidism.

\section{Methods:}

This study was carried out in the Department of physiology, BSMMU, Dhaka between January 2005 to December 2005. A total number of 70 subjects with the age range of 20 to 50 years of both sexes were included in this study, of whom 30 euthyroids ( $\mathrm{TSH}=0.3-5 \mathrm{MIU} / \mathrm{L}$ ) were included in group A (control) and 40 hypothyroids were included in group $\mathrm{B}$ (study group). They were further divided into group $\mathrm{B}_{1}$ consisted of 15 hypothyroids with TSH $<60$ MIU/L and group $B_{2}$ consisted of 25 hypothyroid patients with TSH> $60 \mathrm{MIU} / \mathrm{L}$ or severe group. Most of the hypothyroid patients were under hormone replacement therapy. The duration of the disease varied from 6 months to 5 years. The objectives of the study were explained to each of the subjects and their written consents were taken. Detailed medical history was taken regarding drug intake and their clinical examinations were done. The common features of motor nerve dysfunctions (weakness and atrophy of the muscles of the limbs) were searched for in all patients and all the informations were documented. The hormones were measured by RIA ${ }^{14,15}$ for $\mathrm{TT}_{3}$ and $\mathrm{TT}_{4}$ and IRMA ${ }^{16}$ for TSH. The nerve conduction studies were done by electrophysiological method with a standard NCV machine ${ }^{5,6}$.

The statistical analysis was done by one way ANOVA and $\mathrm{Z}$ test. The study was performed at room temperature.

\section{Results:}

All the parametric variables were expressed as mean ( \pm $\mathrm{SD}$ ). The comparison of the values were done among the different groups. In this study, the mean $\mathrm{TT}_{3}$ and $\mathrm{TT}_{4}$ were significantly lower in hypothyroids in comparison to those of healthy group but the differences were not statistically significant between two hypothyroid groups. (Table-I).
Table-I

The serum of $\mathrm{TT}_{3}$ and $\mathrm{TT}_{4}$ and TSH levels of the study subjects $(n=70)$

\begin{tabular}{lcc}
\hline Groups & $\begin{array}{c}\mathrm{TT}_{3} \\
(\mathrm{nmol} / \mathrm{L})\end{array}$ & $\begin{array}{c}\mathrm{TT}_{4} \\
(\mathrm{nmol} / \mathrm{L})\end{array}$ \\
\hline $\mathrm{A}(\mathrm{n}=30)$ & $2.18 \pm 0.53$ & $129 \pm 28.51$ \\
& $(1.40-3.02)$ & $(71.19-172)$ \\
$\mathrm{B}_{1}(\mathrm{n}=15)$ & $1.31 \pm 0.81$ & $61.21 \pm 29.81$ \\
& $(1.3-2.7)$ & $(40-170)$ \\
$\mathrm{B}_{2}(\mathrm{n}=25)$ & $1.10 \pm 0.85$ & $54.4 \pm 39.31$ \\
& $(0.45-1.25)$ & $(21-165)$ \\
\hline
\end{tabular}

Statistical analysis

\begin{tabular}{lcc}
\hline & \multicolumn{2}{c}{ P value } \\
\cline { 2 - 3 } $\mathrm{A}_{\mathrm{v} \text { vs B }}$ & $<0.01^{* *}$ & $<0.001^{* * *}$ \\
$\mathrm{~A}_{\text {vs B }}$ & $<0.001^{* * *}$ & $<0.001^{* * *}$ \\
$\mathrm{~B}_{1}$ vs B $_{2}$ & $0.75^{\mathrm{NS}}$ & $0.889^{\mathrm{NS}}$ \\
\hline
\end{tabular}

Results are expressed as Mean \pm SD; One-way ANOVA (with Post Hoc Test) was performed as the test of significance. Figures in the parentheses indicate the ranges.

Group $A$ =Euthyroids (control group), Group $\mathrm{B}_{1}=$ Hypothyroids with TSH level $<60 \mathrm{MIU} / \mathrm{L}$, Group $\mathrm{B}_{2}=$ Hypothyroids with TSH level $>60 \mathrm{MIU} / \mathrm{L}$,

$* * *=\mathrm{P}<0.001, * *=\mathrm{P}<0.01$.

$\mathrm{n}=$ Number of subjects, NS=Not significant.

Except diminished or absence of most of the deep tendon reflexes, the typical clinical features of motor neuropathy were absent in all patients.

Nerve study revealed, significantly higher $(\mathrm{P}<0.01)$ distal latency (MDL) and lower $(\mathrm{P}<0.001)$ conduction velocity (MNCV) in both of the hypothyroid groups in comparison to those of the control in median nerve (Table II).

On the other hand, the differences of MDL were not statistically significant between two hypothyroids and also with that of control in ulnar nerve (Table-III).

Again, for common peroneal nerve, this value was higher in both the hypothyroids but it was statistically significant for severe group (Table 4). However, MNCV were significantly, lower in both the hypothyroids for all nerves. (TableII, III, IV).

All these parameters were statistically nonsignificant between two hypothyroid groups.

Again, this study also revealed that, 27 (67.5\%) of the hypothyroid subjects showed the presence of neuropathy by abnormal NCV, of whom 18 (66\%) of the subjects were in severe group and 9 (34\%) were in less severe group. (Table-V). 
Table-II

Nerve conduction parameters for motor function of Median $(M)$ nerve $(n=70)$

\begin{tabular}{lcc}
\hline Groups & $d$ Latency $(\mathrm{m} \mathrm{sec})$ & $\mathrm{NCV}(\mathrm{m} / \mathrm{sec})$ \\
\hline $\mathrm{A}(\mathrm{n}=30)$ & $2.92 \pm 0.338$ & $62.33 \pm 5.274$ \\
& $(2.50-3.50)$ & $(66.00-74.00)$ \\
$\mathrm{B}_{1}(\mathrm{n}=15)$ & $3.59 \pm 0.564$ & $53.30 \pm 5.046$ \\
& $(2.60-4.80)$ & $(43.00-61.00)$ \\
$\mathrm{B}_{2}(\mathrm{n}=25)$ & $3.90 \pm 0.0887$ & $53.68 \pm 6.053$ \\
& $(2.60-6.20)$ & $(44.00-66.00)$ \\
\hline
\end{tabular}

Statistical analysis

\begin{tabular}{lcl}
\hline & \multicolumn{2}{c}{ P value } \\
\cline { 2 - 3 }$A$ vs $B_{1}$ & $<0.010^{* *}$ & $<0.001^{* * *}$ \\
$\mathrm{~A}$ vs $\mathrm{B}_{2}$ & $<0.001^{* * *}$ & $<0.001^{* * *}$ \\
$\mathrm{~B}_{1}$ vs B $_{2}$ & $0.320^{\mathrm{NS}}$ & $0.0991^{\mathrm{NS}}$ \\
\hline
\end{tabular}

Results are expressed as Mean ( \pm Standard deviation); One way ANOVA (Post Hoc Test) was performed as the test of significance, The figures in parenthesis indicate range.

Group A = Euthyroid control group,

Group $\mathrm{B}_{1}=$ Hypothyroids with TSH level $<60 \mathrm{~m} \mathrm{IU} / \mathrm{L}$, Group $\mathrm{B}_{2}=$ Hypothyroids with TSH level $>60 \mathrm{~m} \mathrm{IU} / \mathrm{L}$, $\mathrm{d}$ latency $=$ Distal Latency,

$\mathrm{NCV}=$ Nerve Conduction Velocity,

$* * *=\mathrm{P}<0.001, * *=\mathrm{P}<0.01, \mathrm{n}=$ Number of subjects, NS

$=$ Not Significant.

Table-III

Nerve conduction parameters for Motor function of Ulnar $(U)$ nerve $(n=70)$

\begin{tabular}{lcc}
\hline Groups & d Latency $(\mathrm{m} \mathrm{sec})$ & $\mathrm{NCV}(\mathrm{m} / \mathrm{sec})$ \\
\hline $\mathrm{A}(\mathrm{n}=30)$ & $2.48 \pm 0.207$ & $60.13 \pm 4.790)$ \\
& $(2.00-2.70)$ & $(53.00-68.00)$ \\
$\mathrm{B}_{1}(\mathrm{n}=15)$ & $2.85 \pm 0.806$ & $53.76 \pm 5.309$ \\
& $(2.00-4.90)$ & $(45.00-60.00)$ \\
$\mathrm{B}_{2}(\mathrm{n}=25)$ & $2.87 \pm 0.688$ & $53.26 \pm 5.722$ \\
& $(2.10-4.20)$ & $(45.00-65.00)$ \\
\hline
\end{tabular}

Statistical analysis

\begin{tabular}{lcc}
\hline & \multicolumn{2}{c}{ P value } \\
$\mathrm{A}_{\text {vs B }}$ & $0.113^{\mathrm{NS}}$ & $<0.01^{* *}$ \\
$\mathrm{~A}$ vs $\mathrm{B}_{2}$ & $0.064^{\mathrm{NS}}$ & $<0.001^{* * *}$ \\
$\mathrm{~B}_{1}$ vs B & $1.00^{\mathrm{NS}}$ & $0.779^{\mathrm{NS}}$ \\
\hline
\end{tabular}

Results are expressed as Mean ( \pm Standard deviation); One way ANOVA (Post Hoc Test) was performed as the test of significance, The figures in parenthesis indicate range.

Group A = Euthyroid control group,

Group $\mathrm{B}_{1}=$ Hypothyroids with TSH level $<60 \mathrm{~m} \mathrm{IU} / \mathrm{L}$, Group $B_{2}=$ Hypothyroids with TSH level $>60 \mathrm{~m} \mathrm{IU/L}$, d latency $=$ Distal Latency,

NCV $=$ Nerve Conduction Velocity, ${ }^{* * *}=\mathrm{P}<0.001$, $* *=\mathrm{P}<0.01$, $\mathrm{n}=$ Number of subjects, NS $=$ Not Significant.
Table-IV

Nerve conduction parameters for Motor function of Common Peroneal (CP) nerve $(n=70)$

\begin{tabular}{|c|c|c|}
\hline Groups & d Latency (m sec) & $\mathrm{NCV}(\mathrm{m} / \mathrm{sec})$ \\
\hline \multirow[t]{2}{*}{$A(n=30)$} & $3.60 \pm 0.161$ & $57.63 \pm 4.230)$ \\
\hline & $(3.30-3.90)$ & $(50.00-67.00)$ \\
\hline \multirow[t]{2}{*}{$B_{1}(n=15)$} & $4.28 \pm 0.809$ & $49.00 \pm 3.273$ \\
\hline & (3.30-5.60) & $(43.00-57.00)$ \\
\hline \multirow[t]{2}{*}{$B_{2}(n=25)$} & $2.87 \pm 0.688$ & $53.26 \pm 5.722$ \\
\hline & $(3.40-9.50)$ & $(40.00-56.00)$ \\
\hline \multicolumn{3}{|c|}{ Statistical analysis } \\
\hline & \multicolumn{2}{|c|}{$\mathrm{P}$ value } \\
\hline$A$ vs $B_{1}$ & $0.06^{\mathrm{NS}}$ & $<0.001^{* * *}$ \\
\hline$A$ vs $B_{2}$ & $<0.001 * * *$ & $<0.001^{* * *}$ \\
\hline $\mathrm{B}_{1}$ vs $\mathrm{B}_{2}$ & 0.435 NS & 0.786 NS \\
\hline
\end{tabular}

Results are expressed as Mean ( \pm Standard deviation); One way ANOVA (Post Hoc Test) was performed as the test of significance, The figures in parenthesis indicate range.

Group A = Euthyroid control group,

Group $B_{1}=$ Hypothyroids with TSH level $<60 \mathrm{~m} \mathrm{IU/L}$,

Group $\mathrm{B}_{2}=$ Hypothyroids with TSH level $>60 \mathrm{~m} \mathrm{IU} / \mathrm{L}$,

$\mathrm{d}$ latency $=$ Distal Latency,

NCV $=$ Nerve Conduction Velocity,

$* * *=\mathrm{P}<0.001$,

$\mathrm{n}=$ Number of subjects, NS $=$ Not Significant.

Table-V

Distribution of subjects by NCV $(n=70)$

\begin{tabular}{ccccccc}
\hline Groups & $\mathrm{n}$ & \multicolumn{2}{c}{ Normal NCV } & & \multicolumn{2}{c}{ Abnormal NCV } \\
& & no & $(\%)$ & & no & $(\%)$ \\
\hline A & 30 & 27 & 90 & & 3 & 10 \\
B & 40 & 13 & 32.5 & & 27 & 67.5 *** \\
$\mathrm{B}_{1}$ & 15 & 6 & 40 & & 9 & 60 \\
$\mathrm{~B}_{2}$ & 25 & 7 & 28 & & 18 & 72 \\
\hline
\end{tabular}

Statistical analysis was done by ' $Z$ ' test as a test of significance.

$\mathrm{Z}=6.243$

Group A=Euthyroid (control) group,

Group B= Hypothyroid group,

Group $B_{1}=$ Less severe hypothyroids,

Group $\mathrm{B}_{2}=$ Severe hypothyroids,

$* * *=\mathrm{P}<0.001$

$\mathrm{n}=$ Number of subjects, NCV=Nerve conduction velocity. 


\section{Discussion:}

The hypothyroid patients showed no remarkable clinical signs of motor neuropathy with the exception of a few like diminished or absence of most of the deep tendon reflexes but all the hypothyroids had significantly ( $\mathrm{P}<0.01$ ) lower $\mathrm{TT}_{3}$ and $\mathrm{TT}_{4}$ levels compared to euthyroids.

Nerve conduction abnormalities were observed in a significant number of hypothyroid patients by electrophysiological studies. However, the nerve conduction parameters in the control group were similar or nearer to normal reference values $.4,9,11-13$

Some other groups of investigators had also observed the slowing of nerve conduction velocities in different peripheral nerves but they did not mention about the individual values of the parameters like motor distal latency (MDL) and motor nerve conduction velocity (MNCV). ${ }^{5-6,14,16}$

Both the hypothyroid groups showed higher motor distal latencies (MDL) with lower motor nerve conduction velocities (MNCV) for median, ulnar and common peroneal nerves. Again, the nerve conduction study revealed the predominant impairment in the median nerve among the three nerves as the differences of all the parameters were statistically significant between euthyroids and both the less severe and severe hypothyroids in this nerve. The investigators of different countries also mentioned about the similar involvement of median nerve $\mathrm{e}^{1,5,6,9,14,16}$.

The mechanisms involved in the development of neuropathy in hypothyroidism are not yet fully established but different investigators suggested that the weight gain in hypothyroids may be a contributory factor for neuropathy. In addition, the deposition of mucopolysaccharide or the myxedematous tissue may also lead to compression over the peripheral nerves and thereby results in swelling and degeneration of them ${ }^{4,6}$.

It has also been suggested that the thyroid hormones stimulate the mitochondrial respiratory activity to produce energy in the form of ATP during aerobiosis under normal physiological condition. Hormones also increase the ATPase activity and consequently $\mathrm{Na}^{+} / \mathrm{K}^{+}$pump activity in this group of patients. Therefore, deficiency of ATP and reduced ATPase and decreased $\mathrm{Na}^{+} / \mathrm{K}^{+}$pump activity cause subsequent alteration of pump dependent axonal transport and thereby may lead to peripheral neuropathy ${ }^{14}$. Decrease glycogen degradation may also leads to energy deficit in hypothyroidism ${ }^{5,6,14,16}$. Though the neuropathy due to compression and the peripheral neuropathy due to axonal degeneration are not fully distinguished, most likely, there may be a combination of both these two factors, which results in the development of peripheral as well as the motor neuropathy in hypothyroidism ${ }^{4}$.

Therefore, this study revealed that motor neuropathy is not an uncommon manifestation in patients suffering from hypothyroidism even in our population.

\section{References:}

1. Dyck PF, Lambert EH. Poly neuropathy associated with hypothyroidism. J Neuropathol Exp Neurol 1970; 29: 631-658.

2. Edwards CRW, Toft AD, Walker BR. Endocrine disease. In: Haslett C, Chilvers E R, Hunter J A A, Boon N A. (editors). Davidson's principles and practice of medicine. London: Harcourt Brace and Company; 1999; pp 559-575.

3. Ganong WF. Review of medical Physiology. 21nd ed. Boston : Mc Graw Hill; 2003. 320p.

4. Preston DC. Electromyography and Neuromuscular Disorders, Clinical - Electrophysiological Correlations. $1^{\text {st }}$ ed. USA: Butterworth- Heinemann; 1998. 561p.

5. Rao SN, Katiyar BC, Nair KRP, Misra S. Neuromuscular status in hypothyroidism. Acta Neurol Scand 1980; 61:167-77.

6. Shirabbe T, Tawara S, Tetrao A, Araki S. Myxedematous polyneuropathy: a light and electron microscopy study of peripheral nerve and muscle. J Neurol Neurosurg Psychiatry 1975; 38: 241-47.

7. Record from the Thyroid Clinic, Nuclear medicine and Ultrasound Centre, DMCH, Dhaka.

8. Sultana S. Some aspects of electrophysiological changes of peripheral nerves in diabetic patients of different duration [M Phil thesis] [Dhaka]: Bangabandhu Sheikh Mujib Medical University; 2003. 114 p.

9. Total Triiodothyronine $\left(\mathrm{T}_{3}\right)$ Radioimmunoassay Kit (PR) IMK422 [Manual] 2005, Department Of Isotope. China Institute of Atomic Energy, Beijing.

10. Total Thyroxine $\left(\mathrm{T}_{4}\right)$ Radioimmunoassay Kit (PR) IMK-419 [Manual] Beijing Atom Hightech Co Ltd., Beijing. 2005.

11. TSH Immunoradiometric assay Kit IMK-432 [Manual], Beijing Atom Hightech Co Ltd. , Beijing2005

12. Kimura J. Electrodiagnosis in diseases of nerve and muscle: principles and practice. $2^{\text {nd }}$ ed. Philadelphia : F.A. Davis; 1989. $103 \mathrm{p}$.

13. Misra UK, Kalita J. Late response Clinical Neurophysiology; nerve conduction, electromyography and evoked potentials. $1^{\text {st }}$ ed. New Delhi : Churchill Livingstone Pvt Ltd. 1999. 20 p.

14. Nemni R, Bottacchi E, Fazio R, et al. Poly neuropathy in hypothyroidism: Clinical, Electrophysiological and morphological findings in 4 cases. J Neurol Neurosurg Psychiatry 1987; 50: 14541460.

15. Palumbo CF, Szabo RM, Olmsted SL. The effects of hypothyroidism and thyroid replacement on the development of carpal tunnel syndrome. J Hand Surg 2000; 734-739.

16. Torres CF, Moxley RT. Hypothyroid neuropathy and myopathy: clinical and electrodiagnostic longitudinal findings. J Neurol 1990; 237:271-274.

17. Crevasse LE, Logue RB. Peripheral neuropathy in myxedema. Ann Intern Med 1959; 50: 1433-37. 